\section{PRAGUE CONFERENCE ON THE USE OF X-RAYS IN THE METAL INDUSTRIES}

$\mathrm{T}$ HE Society of Czechoslovak Mathematicians and Physicists arranged an X-ray Conference held in Prague during November 28-December 1. About two hundred attended, and the conference had an air of warm cordiality and collaboration ; lost connexions with the Western world were re-established, and the Czech X-ray workers, isolated by six years of German occupation, came into personal contact for the first time with the scientific workers of the United Nations and their publications. The conference, which was the first of its kind in liberated Czechoslovakia, was opened by Dr. M. Hampl, who greeted the foreign guests and recalled victims of the terror of the German occupation; naming Prof. V. Dolejšek, Prof. F. UIrich, Prof. F. Záviška, Dr. Radim Nováček, Dr. Miklenda, Dr. L. Slavíková, Prof. Simek, Dr. J. Klein, Prof. Rosický, Dr. Žadkevič, Prof. Sahánek, Dr. Köppel (see also Nature, 157, 332 ; 1946).

In Czechoslovakia there are now about forty X-ray specialists working in various parts of the country. They are members of the Society of Czechoslovak Mathematicians and Physicists, which arranged the conference as the result of requests originating from the metal industries.

Prof. F. Slavík and Dr. V. Kunzl delivered addresses in memory of two pioneer Czech workers in the field of X-rays, who died under the German terror : Prof. F. Ulrich and Prof. V. Dolejšek. Prof. Ulrich was one of the first to use X-rays as a tool in crystallography, his work starting immediately after the First World War. Prof. Dolejšek, who died in a camp in Terezín, was an outstanding X-ray spectroscopist. As a pupil of Prof. Siegbahn, he started work on Moseley's law, and used gas tubes in the long-wave $\mathrm{X}$-ray field.

The contributions to the conference will be published in full as a separate volume in Czech, with English and Russian abstracts.

Dr. J. Bačkovský (Škoda Works) discussed the biological action of $\mathrm{X}$-rays and the determination of the tolerance of organisms. M. Baimler (Skoda Works) spoke on the serial testing of light-alloy castings by radiography and about the design of a modern test room with jigs for mass radiography of castings. Costing of different methods of inspection was compared. He then discussed the choice of an X-ray tube for radiography. Dr. J. Bénard (Faculté des Sciences, Paris) spoke about the increase in accuracy of the powder camera for back reflexions and its application in France to the chemistry of oxides and structure of metals. Especially interesting were the problems of the oxidation of iron and of the polishing of metals. Dr. J. Beneš (Charles University, Prague) spoke about the methods of determining the orientation of the electric axis in a crystal by Laue photographs, with application to quartz. Dr. G. W. Brindley (University of Leeds) sent a contribution dealing with a quantitative analysis by means of $\mathrm{X}$-ray diffraction methods and its limitations. Prof. E. G. Cox (University of Leeds) spoke on crystallographic $\mathrm{X}$-ray tubes with rotating anodes, such as have been developed at Leeds.

Dr. F. Faltus (Skoda Works) discussed the practical use of $X$-rays and $\gamma$-rays in welding. There is often no direct correlation between the conspicuous. ness of a fault and its importance; often the most dangerous faults, such as cracks, are difficult to detect. One must not overlook also the educational and the psychological element of the X-ray control on the welder. Often a saving is made by testing only selected parts of the weld, located by previous statistical analysis.

Dr. J. Feifer (Škoda Works) described how elastic and plastic deformation affects spacings, especially as shown by the back reflexion method. Deformations, translations and rotations of small grains, and also twinning, were discussed. Back reflexions are affected by these processes ; the width and intensities of the diffraction lines undergo changes. Prof. A. I Glazunov and Dr. L. Jeníček described X-ray analysis of electrolytic deposits of metals. Often a new unusual lattice of a metal appears, and $\mathrm{X}$-rays are very helpful in determining its kind, deformations, grain size and orientation, helping thus to improve the technical product. Dr. J. Hrdlička dealt with the sensitivity of photographic emulsions for X-rays. Dr. L. Janko spoke about the help of radiography in a corrosion laboratory. Cavities in a layer of lead on tinned iron, intended as a corrosion protection, were detected. Under pressure, these cavities can be perforated and thus decrease the corrosion resistance of the layer. Dr. L. Jeníček spoke about the use of $\mathrm{X}$-rays in the study of foundry sands, with reference to the mechanism of their binding in the wet and dry state. X-rays can be linked up with research by the electron microscope.

Dr. A. Ježek (Baťa, Zlín) dealt with the fatigue of materials, which can be studied by X-rays a long time before the first cracks actually appear. X-rays reveal such changes as a shift of the mosaic, orientation of the grain, decrease of the internal strains and recrystallization, leading finally to failure. All these symptoms can be used to predict fatigue in the installations under working conditions.

Dr. F. Khol (Škoda Works) gave a review of back reflexion methods as used for precision measurement of lattice constants. A method of calculation was given. Grain size of the tested material and of the film was discussed. Errors due to film deformation can be eliminated by impressing on the film a reference net.

Dr. A. Kochanovská (Škoda Works) spoke about the splitting of the lines into several sharp components when the back-reflexion method is used with a rotated polycrystalline coarse-grain specimen. The explanation by several German authors that the splitting is due to the refraction of $\mathrm{X}$-rays has proved to be wrong. It can be explained simply from the geometry of a primary beam of a finite width, from which a few strong rotating reflexions separate as a series of discrete circles. Dr. A. Kochanovská then recommended the following method for determining the deformation or anisotropy of crystals in a polycrystalline material. In an isotropic material the individual crystals are deformed in all directions equally. In an anisotropic material this is not so, and as examples measurements on steel and aluminium were given.

Dr. J. Kuba (Ceskomoravská, Prague) discussed the problem of protection of persons against X-rays. Protection is important from social grounds, and legal regulations are being prepared. He then spoke about the testing of bearings and bearing metals by radiography. Modern apparatus for continuous testing of bearings was described and typical faults shown. 
Dr. P. Lacombe (France) contributed jointly with Prof. Guinier a paper on the use of a curved crystal as a monochromator and as a means for focusing X-rays, which in conjunction with a powder camera gives very sharp contrast photographs. Small quantities of impurities can be detected and complicated structures can be analysed.

Dr. V. Petržílka (Charles University, Prague) described an X-ray method for orientation of cut quartz crystal plates by means of an adapted Seeman spectrograph. A small indentation in its knife edge shows on the $K$ and $L$ lines of the spectrum on the film as black spots. The position of these spots is a function of the orientation of the crystals, and from one photograph it is possible to determine both principal angles and to control and test cut or finished quartz plates.

Dr. P. Skulari (Ceskoslovenská Zbrojovka, Prague) discussed the close collaboration of the X-ray worker with the engineer. By such collaboration, technolog. ical processes can be corrected and guided, density and porosity determined and casting controlled. $\mathrm{He}$ also described how X-ray analysis elucidated the working properties of zinc and zinc alloys which possess a hexagonal structure. This structure is sensitive to working processes. Anisotropy and twinning are also contributing causes to the working properties. The best mechanical properties are achieved by slow cold-working or by repair of the damaged structure by annealing followed by quenching. Dr. I. Smoler gave his experiences on the X-ray analysis of crystalline compounds, chiefly inorganic, by the powder method. Analysis consisted of comparison of the diffraction pattern with a standard, or calculation of the lattice. The method was applied to titanium white (rutile-anatase), to refractory materials, to cements for dentists, and many other substances. Dr. B. G. Simek (Coal Research Institute, Prague) spoke about the radiography of coals. In black coal inorganic materials can be detected, whereas brown coal gives continuous blackening. The structure of coke can be investigated by filling its cavities with barium sulphate. Brickettes were investigated by adding lead soap in the binder. He then spoke about the X-ray analysis of coals. Reactivities of graphite and various cokes were measured and compared with $\mathrm{X}$-ray results, giving the size of the crystallites. The powder method was used and the photographs measured with a recording microphotometer. Colloid dispersions of carbon in pitch and their properties were also studied.

Major J. Sterner (U.S. Army) spoke about some recent developments of apparatus for X-ray purposes, such as vibrating microphotometers, registering the first derivative of blackening, and $\mathrm{X}$-ray planigraphy.

Prof. P. Urbain (Institut Ernest Denis, Prague) referred to the use of powder methods in the investigation of hydrated aluminium, magnesium and iron silicates in clays and soils. The specimens should be purified by electrophoresis with high values of electric fields to eliminate quartz, oxides and carbonates. The diffraction pattern is thus simplified. The metacolloids can then be classified according to their long spacings into four groups : Kaolinite-halloysite (6.959.65 A.) of aluminium type; nontronite (10-11 A.) containing iron and also aluminium; sepielite (11$13 \cdot 5$ A.) containing magnesium and also aluminium; montmorillonite (14-15 A.) containing aluminium and magnesium.

Dr. V. Vand (Lever Brothers, Port Sunlight) contributed a description of the progress in the construc- tion of X-ray tubes and apparatus in Great Britain and the United States. Powder and focusing cameras and moving film techniques were also described.

M. Vinopal (Meta, Prague) gave a general outline of the evolution and history of the Czechoslovak X-ray industry.

Dr. J. Wanka (Society for Chemical and Mining Manufacture) spoke about the testing by radiography of a complicated chemical plant. Welds and boilers were tested, and as accessibility was very difficult, various methods were used. Dr. K. Waitzmann (Research and Testing Institute for Building Materials, Prague) described the testing of materials by means of $\gamma$-rays from radium, radon and mesothor. ium. The time of exposure is shortened by reinforcing foils. In steel and concrete, cavities of different sizes can be detected. By means of a comparison wedge, the thickness of the cavities can be determined. Mrs. Wooster (Cavendish Laboratory, Cambridge) spoke about the use of X-rays in conjunction with the Weissenberg camera in the study of orientation of crystals, and in the testing of industrial diamonds. Dr. L. Zachoval (Ako, Ceský Brod) sent a contribution about the methods of sensitometry of $\mathrm{X}$-ray emulsions and appealed for a standardization of the procedure. A Scheiner astroboscopic disk and a source of controlled X-ray output is recommended; for lower accuracy, a wedge is sufficient.

Dr. Kunzl (Charles University, Prague) summarized the results of the meetings.

V. VAND.

\section{VENEREAL DISEASE IN WEST AFRICA}

\author{
By MAJOR R. R. WILLCOX
}

Late Command Venereologist, West African Command

\section{Incidence}

$T$ HE incidence of venereal disease in West African natives is very high indeed, and is rapidly on the increase. The exact number of cases in the Colonies is difficult to assess, but in British coloured troops in Nigeria, for example, the gonorrhcea rate alone was more than 60 per cent per annum; while the venereal disease rate in Gold Coast troops was 50 per cent per annum; in Sierra Leone 28 per cent; and in the Gambia as low as 12 per cent.

Gonorrhcea is by far the most common venereal disease, and the women in the larger towns are nearly all infected. The virtual total absence of facilities to treat the women on any scale at all makes the problem a most acute one. Soft sore and lymphogranuloma inguinale are both very prevalent, while syphilis, though taking fourth place, is also very rife.

\section{Treatment Facilities}

The British Army, on the whole, is organised to give adequate treatment to its personnel and to render them free from infection. The main difficulty is that the men are constantly being reinfected by the women. Some hospitals have venereal diseases clinics attached to them; while at others, such as Bathurst in the Gambia and Lagos in Nigeria, actual clinics have recently been opened. The relative numbers of female attendances at these centres are not many. Most civilian hospitals have a venereal diseases ward for males but there are usually no darkground condensers available for diagnostic purposes, 